\title{
Lung cancer patients with synchronous colon cancer
}

\author{
KOICH KURISHIMA ${ }^{1}$, KUNIHIKO MIYAZAKI ${ }^{2}$, HIROKO WATANABE ${ }^{3}$, TOSHIHIRO SHIOZAWA ${ }^{3}$, \\ HIROICHI ISHIKAWA ${ }^{1}$, HIROAKI SATOH ${ }^{4}$ and NOBUYUKI HIZAWA ${ }^{3}$ \\ ${ }^{1}$ Division of Respiratory Medicine, Tsukuba Medical Center Hospital, Tsukuba, Ibaraki 305-8558; \\ ${ }^{2}$ Division of Respiratory Medicine, Ryugasaki Saiseikai Hospital, Ryugasaki, Ibaraki 301-0854; \\ ${ }^{3}$ Division of Respiratory Medicine, Faculty of Medicine, University of Tsukuba, Tsukuba, Ibaraki 305-8575; \\ ${ }^{4}$ Division of Respiratory Medicine, Mito Medical Center, University of Tsukuba, Mito, Ibaraki 310-0015, Japan
}

Received February 10, 2017; Accepted July 4, 2017

DOI: $10.3892 / \mathrm{mco} .2017 .1471$

\begin{abstract}
Lung and colon cancers are two of the most common malignancies, which, in some cases, may develop synchronously. In the present study, the treatment and outcome of patients with synchronous lung and colon cancers were reviewed. During a 76-month study period, from April 2009 up to July 2016, 17 (0.54\%) of 3,102 patients with lung cancer were diagnosed with colon cancer within 1 month. Heavy smoking and obesity were not specific factors in these patients. A total of 9 patients succumbed to lung cancer during the study period. Survival in asymptomatic patients was longer compared with that in symptomatic patients (median survival, 80 vs. 23.2 months, respectively; $\mathrm{P}=0.007$ ). Although the incidence of synchronous occurrence of these two cancers may be low, particularly in patients diagnosed incidentally, such patients should be treated accordingly. Future genetic and epidemiological studies are required to elucidate the potential connection between lung and colon cancer.
\end{abstract}

\section{Introduction}

Patients with lung cancer may develop other malignancies $(1,2)$, as may those with colon cancer (3). Epidemiologically, it has been suggested that cigarette smoking is closely associated with an increased risk of cancer in various organs, including the lung and the colon $(4,5)$. Lung cancer is primarily known to be associated with upper aerodigestive tract cancer, but its association with gastrointestinal cancer should not be overlooked. In fact, lung cancer appears to be one of the most common second primary cancers in patients with colon cancer (4). However, there are few reports of the treatment and outcome of patients with synchronous lung and colon cancers (6-8). Additionally, the treatments for these cancer patients and their

Correspondence to: Professor Hiroaki Satoh, Division of Respiratory Medicine, Mito Medical Center, University of Tsukuba, Miya-machi 3-2-7, Mito, Ibaraki 310-0015, Japan

E-mail: hirosato@md.tsukuba.ac.jp

Key words: lung cancer, colon cancer, synchronous outcomes are scarcely reported (6-8). To evaluate the clinical information, we herein review our experience with lung cancer patients who developed synchronous colon cancer.

\section{Patients and methods}

Patient classification and staging. The medical records and pathology reports of all lung cancer patients at the Division of Respiratory Medicine in our four tertiary hospitals between April 2009 and July 2016 were reviewed. The collected data included sex, age at diagnosis of colon and lung cancer, smoking history, comorbid diseases, histology and clinical stage of lung cancer, type of treatment and survival from the date of diagnosis of lung cancer. The symptomatic group of patients were defined as those with symptoms of either or both lung and colon cancers. In the present study, synchronous cancers were defined as those diagnosed within 1 month.

The asymptomatic group of patients were defined as those detected incidentally by mass screening during follow-up studies for diseases other than these two cancers, and during lung or colon cancer workup. The diagnoses of colon and lung cancer were confirmed pathologically in all the patients and the histopathological cancer types were confirmed by the World Health Organization classification. Staging was performed according to the 7th edition of the International Union for Cancer Control TNM classification of malignant tumors (http://www.uicc. org/sites/main/files/private/TNM_Classification_of_Malignant_ Tumours_Website_15\%20MAy2011.pdf), using chest computed tomography (CT), brain magnetic resonance imaging, bone scan, endoscopy and ultrasonography. In a proportion of the cases, fluorodeoxyglucose (FDG)-positron emission tomography (PET) was used.

Statistical analysis. The statistical significance of the differences between the symptomatic and asymptomatic patient groups were determined using the Mann-Whitney and Chi-squared test. Survival curves were assessed with the Kaplan-Meier method and the log-rank test. Survival was defined as the time from the initiation of the first therapy or supportive care until death or the last follow-up and was calculated in months. The effects of clinicopathological factors on survival were analyzed with the Cox proportional hazards model. Statistical analyses were performed using SPSS 10.1 


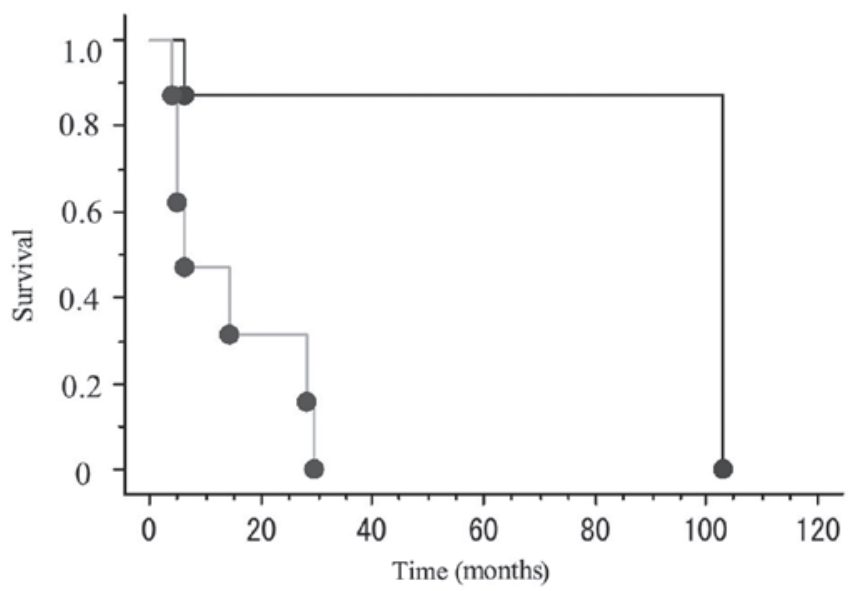

Figure 1. Comparison of survival between asymptomatic patients (upper line) and symptomatic patients (lower line). There was a statistically significant difference in survival between the two groups of patients $(\mathrm{P}=0.007)$.

for Windows (SPSS Inc., Chicago, IL, USA) and $\mathrm{P}<0.05$ was considered to indicate statistically significant differences. Access to the patients' medical records was approved by the Ethics Committee of Mito Medical Center at the University of Tsukuba Hospital (NO16-01).

\section{Results}

Patient characteristics. During the study period, from April 2009 up to July 2016, 17 (0.54\%) of 3,102 patients with primary lung cancer were diagnosed with synchronous colon cancer. The clinicopathological characteristics of the 17 patients with synchronous lung and colon cancers are summarized in Table I. Of the 17 patients, 13 were male. The median age at diagnosis was 72 years (range, 60-86 years). Of the 17 patients, $13(76.5 \%)$ were smokers and 11 were $>30$-pack-year smokers. Only $2(11.8 \%)$ of the patients were overweight [body mass index $\left.(\mathrm{BMI}) \geq 25.0 \mathrm{~kg} / \mathrm{m}^{2}\right]$ at the time of diagnosis of the two cancers. A total of 13 patients had non-small-cell lung cancer (NSCLS), and 15 (88.2\%) had sigmoid colon or rectal cancer.

Treatment and outcome. In the 17 patients with synchronous lung and colon cancers, 9 patients were asymptomatic and the remaining 8 were symptomatic. The clinical stage and treatment for these two cancers in the two patient groups are summarized in Table II. Apart from the treatment for colon cancer, there were no statistically significant differences between the two groups. The numbers of patients who received therapy for colon cancer first, those who received therapy for lung cancer first, and those who received supportive care alone, are listed in Table III. There was no statistically significant difference between the two groups of patients.

During the study period, 9 patients succumbed to their disease. The cause of death in all 9 patients was directly associated with lung cancer. The median survival in the asymptomatic group of patients was 80 months and that in the symptomatic group of patients 23.2 months. The difference in survival between the two groups of patients was statistically significant ( $\mathrm{P}=0.007$; Fig. 1).
Table I. Characteristics of 17 patients with synchronous lung and colon cancers.

\begin{tabular}{lr}
\hline Characteristics & No. $(\%)$ \\
\hline Age (years) & \\
Median, range & $72,60-86$ \\
Sex & \\
Male & $13(76.5)$ \\
Female & $4(23.5)$ \\
Smoking habit & \\
Former- or current smoker & $13(76.5)$ \\
Never smoker & $4(23.5)$ \\
Body mass index (kg/m²) & $14(82.4)$ \\
$\geq 20$ & $2(11.8)$ \\
$\geq 25$ & \\
Lung cancer & $13(76.5)$ \\
Non-smallcell lung cancer & $4(23.5)$ \\
Smallcell lung cancer & \\
Colorectal cancer & $15(88.2)$ \\
Sigmoid colon or rectal cancer & $2(11.8)$ \\
Others & \\
Disease detection & \\
Asymptomatic & \\
Symptomatic & \\
\hline Detected by mass screening during a follow-up survey for diseases \\
other than lung and colon cancer.
\end{tabular}

Table II. Differences between SCLC patients with and without ILD.

\begin{tabular}{lccc}
\hline & $\begin{array}{c}\text { Patients } \\
\text { with } \\
\text { ILD }\end{array}$ & $\begin{array}{c}\text { Patients } \\
\text { without } \\
\text { ILD }\end{array}$ & P-value \\
\hline Age & & & 0.489 \\
Median, range (years) & 68,5880 & $70,27-86$ & \\
Sex & & & 0.999 \\
Male & 14 & 280 & \\
Female & 1 & 37 & \\
Performance status & & & 0.999 \\
0-1 & 13 & 265 & \\
2-4 & 2 & 52 & \\
Clinical stage & & & 0.999 \\
Early & 7 & 152 & \\
Advanced & 8 & 165 & \\
Treatment & & & 0.079 \\
Chemotherapy & 13 & 263 & \\
Surgery + chemotherapy & 2 & 24 & \\
Chest irradiation & 0 & 25 & \\
Supportive care & 0 & 5 & \\
\hline
\end{tabular}

SCLC, smallcell lung cancer; ILD, interstitial lung disease. 
Table III. Sequence of treatments among patients with synchronous lung and colon cancer.

\begin{tabular}{lccc}
\hline \multirow{2}{*}{$\begin{array}{l}\text { Treatment } \\
\text { sequence }\end{array}$} & $\begin{array}{c}\text { Asymptomatic } \\
\text { group }\end{array}$ & $\begin{array}{c}\text { Symptomatic } \\
\text { group }\end{array}$ & P-value \\
\cline { 2 - 3 } $\begin{array}{l}\text { Treatment for } \\
\text { colon cancer first }\end{array}$ & 5 & 2 & 0.117 \\
$\begin{array}{l}\text { Treatment for } \\
\text { lung cancer first } \\
\begin{array}{l}\text { Supportive care } \\
\text { alone }\end{array}\end{array}$ & 4 & 3 & \\
\hline
\end{tabular}

\section{Discussion}

Lung cancer and colon cancer are two of the most common malignancies and among the leading causes of cancer-related mortality (9). Particularly in developed countries, these cancers are a major public health burden (9). There is a possibility that this combination may be more common than initially considered, if endoscopically treatable early colon cancer is taken into consideration. It is generally accepted that cigarette smoking plays an important role in lung carcinogenesis (4). In addition, epidemiological data suggested that obesity is associated with an increased risk of colon cancer (10). Diabetes and high dietary meat intake are also associated with an increased risk of colon cancer (11). In the present study, there were 4 notable findings: First, we identified that $17(0.54 \%)$ of 3,102 patients with lung cancer had synchronous colon cancer. In the present study, $13(76.5 \%)$ of the 17 patients were smokers, 11 of whom were $>30$-pack-year smokers. However, only $5(29.4 \%)$ had one of two smoking-related histological types of lung cancer, namely squamous cell carcinoma and small-cell lung carcinoma (SCLC). In addition, only 2 (11.8\%) patients were overweight $\left(\mathrm{BMI} \geq 25.0 \mathrm{~kg} / \mathrm{m}^{2}\right)$ at the time of diagnosis. These results suggested that several known and unknown factors may exhibit a complex association with the synchronous development of these two common cancers. Second, $15(88.2 \%)$ of the 17 patients had colon cancer at the lower part of the large intestine, namely rectal cancer $(n=8)$ and sigmoid cancer $(n=7)$. Metastases from lung cancer to the descending colon and rectum are extremely rare, although there have been some case reports $(12,13)$. However, it is generally accepted that these lower parts of the large intestine are the most common sites where primary colon cancer develops (14). Third, the cause of death of the 9 patients who succumbed to the disease during the study period were directly associated with primary lung cancer (7 NSCLCs and 2 SCLCs). Excluding 3 patients who were lost to follow-up, 4 of the 5 patients who remain alive underwent surgical resection of lung cancer. Our results suggested that lung cancer is more likely to be the primary prognostic cancer rather than colon cancer. However, appropriate evaluation of the clinical stage is crucial for determining the optimal therapeutic strategy and predicting the patients' prognosis. It has not been fully elucidated why the prognosis of symptomatic patients was poorer compared with that of asymptomatic patients. It was hypothesized that the lung cancers in the latter group were more slow-growing. The limited number of patients and the short period of follow-up may have affected the results. Fourth, among the 17 patients, two colon cancers (1 rectal and one sigmoid colon cancer), were detected by PET/CT during the workup of primary lung cancer. Pezzuto et al also reported a case exhibiting FDG uptake on PET/CT (15). New diagnostic modalities, such as PET/CT, may provide important clinical information for patients with this rare condition $(16,17)$.

There were certain limitations to the present study: The study was conducted only on a database of lung cancer patients, whereas it should also be conducted on a database of colon cancer patients. In addition, the retrospective design limits the generalization of the results. In light of our experience, it is appropriate to consider heightened surveillance of patients with synchronous lung and colon cancers, as early diagnosis and standard therapy are the only chance for long-term survival and cure. Swift evaluation of signs or symptoms that are suggestive not only of lung cancer but also of colon cancer is recommended. Although the incidence of synchronous lung and colon cancers may be low, future genetic and epidemiological studies are required to elucidate the potential connection between these two types of cancer.

\section{References}

1. Kurishima K, Satoh H, Kagohashi K, Homma S, Nakayama H, Ohara G, Ishikawa $\mathrm{H}$ and Hizawa N: Patients with lung cancer with metachronous or synchronous gastric cancer. Clin Lung Cancer 10: 422-425, 2009.

2. Ghosh SK, Roland NJ, Kumar A, Tandon S, Lancaster JL, Jackson SR, Jones A, Lewis Jones H, Hanlon R and Jones TM: Detection of synchronous lung tumors in patients presenting with squamous cell carcinoma of the head and neck. Head Neck 31: 1563-1570, 2009

3. Kato T, Suzuki K, Muto Y, Sasaki J, Tsujinaka S, Kawamura YJ, Noda H, Horie H, Konishi F and Rikiyama T: Multiple primary malignancies involving primary sporadic colorectal cancer in Japan: Incidence of gastric cancer with colorectal cancer patients may be higher than previously recognized. World J Surg Oncol 13: 23, 2015.

4. Malhotra J, Malvezzi M, Negri E, La Vecchia C and Boffetta P: Risk factors for lung cancer worldwide. Eur Respir J 48: 889-902, 2016.

5. Ezuka A, Sakai E, Kawana K, Nagase H, Kakuta Y, Uchiyama S, Ohkubo H, Higurashi T, Nonaka T, Endo H, et al: Association between factors associated with colorectal cancer and rectal aberrant crypt foci in humans. Oncol Lett 10: 3689-3695, 2015.

6. Yamanaka S, Sakamoto A and Tomoyasu H: Synchronous multiple primary lung and colon cancers. Kyobu Geka 66: 882-885, 2013 (In Japanese).

7. Nosaka S, Yamauchi N, Sasaki T, Hanada T and Tamura K: Clinical study of synchronous double cancers of the lung and digestive tract. Kyobu Geka 51: 400-402, 1998 (In Japanese).

8. Imataka A, Satoh H, Yamashita YT, Kamma H, Ohtsuka M and Sekizawa K: Synchronous presentation of adenocarcinoma in lung and colon. Australas J Cancer 1: 78-80, 2000.

9. Allemani C, Weir HK, Carreira H, Harewood R, Spika D, Wang XS, Bannon F, Ahn JV, Johnson CJ, Bonaventure A, et al: Global surveillance of cancer survival 1995-2009: Analysis of individual data for $25,676,887$ patients from 279 population-based registries in 67 countries (CONCORD-2). Lancet 385: 977-1010, 2015.

10. Bardou M, Barkun AN and Martel M: Obesity and colorectal cancer. Gut 62: 933-947, 2013.

11. Aykan NF: Red Meat and colorectal cancer. Oncol Rev 9: 288, 2015.

12. Yamagishi H, Sakamoto T, Matsuda T, Nakajima T and Saito Y: Solitary metastatic colon cancer showing a small depressed configuration. Intern Med 51: 2321-2324, 2012. 
13. Miyazu K and Kobayashi K: Rectal metastasis from lung cancer; report of a case. Kyobu Geka 65: 165-167, 2012 (In Japanese).

14. Dinning JP, Hixson LJ and Clark LC: Prevalence of distal colonic neoplasia associated with proximal colon cancers. Arch Intern Med 154: 853-856, 1994.

15. Pezzuto A, Mariotta S, Fioretti F and Uccini S: Metastasis to the colon from lung cancer presenting with severe hyponatremia and dyspnea in a young male: A case report and review of the literature. Oncol Lett 5: 1477-1480, 2013.
16. Chen SH, Chan SC, Chao YK and Yen TC: Detection of synchronous cancers by fluorodeoxyglucose positron emission tomography/computed tomography during primary staging workup for esophageal squamous cell carcinoma in Taiwan. PLoS One 8: e82812, 2013.

17. Caballero Gullón L, Borrego Dorado I and Vázquez Albertino R: A colon adenocarcinoma and a pharyngeal carcinoma incidentally detected by means of (18)F-FDG PET in a patient diagnosed of lung cancer. Rev Esp Med Nucl 29: 29-31, 2010 (In Spanish). 